\title{
Knowledge of psychosocial factors associated with low back pain amongst health science students: a scoping review
}

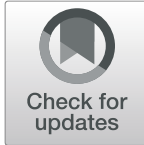

Kelsey L. Lewis ${ }^{*}$ (1) and Patrick J. Battaglia

\begin{abstract}
Background: Low back pain is a burden worldwide and biological, psychological, and social mechanisms play a role in its development and persistence. Current guidelines support care using the biopsychosocial model. However, biomedical constructs dominate clinician training, and it is unknown the extent to which health science students understand the psychosocial determinates of a patient's low back pain. Therefore, the aim of this scoping review is to report health science students' current knowledge of psychosocial factors associated with low back pain.

Methods: A scoping review framework was used to search electronic databases for research examining health science students' knowledge of psychosocial factors associated with low back pain. The nature and findings of the studies are highlighted using the data charting tool. Each study was analyzed to determine the type of outcome measurement used. Scores were compared to minimum accepted scores, between disciplines, as education advanced, and after educational modules.

Results: Fourteen studies published between 2004 and 2019 were identified. Seven healthcare disciplines were represented. In total, 12 different measurement tools were utilized. In 9 studies students demonstrated inadequate knowledge of psychosocial factors associated with low back pain. Three tools compared disciplines and nationalities. Three tools were associated with practice behavior. Eight studies showed improvement as students' education advanced, and 3 studies demonstrated improvements in knowledge after implementation of pain education modules of varied lengths. Of those, two showed significant improvement.

Conclusions: Health science students in these studies had substandard understanding of psychosocial factors associated with low back pain. Dedicated pain education has the potential to improve low back pain understanding, resulting in more guideline appropriate care recommendation.
\end{abstract}

Keywords: Psychosocial factors, Low back pain, Health occupation students, Education

\section{Background}

Low back pain is a costly and prevalent global health issue [1-3]. It is the leading cause of disability worldwide [3]. According to the Global Burden of Disease study in 2015, there has been a $54 \%$ increase in years lived with disability from low back pain since 1990 [4]. Often multiple and simultaneous mechanisms cause low back pain requiring a biopsychosocial perspective to optimize care [1]. Although tissue damage may have been the origin of low back pain, in the majority of cases a specific physical injury cannot be

\footnotetext{
* Correspondence: Kelsey.lewis@loganhealthcenters.com Logan University Health Centers, Logan University, 1851 Schoettler Road, Chesterfield, MO 63017, USA
}

identified [5]. Numerous psychosocial factors interact with the neurobiology of ongoing low back pain, which is often refractory to monotherapy approaches [5]. Depression, distress, depressive mood and somatization are predictors of chronicity and disability in low back pain patients [5]. Psychological factors associated with chronic pain in general (i.e. not just low back pain) include depression, anxiety, post-traumatic stress disorder, fear avoidance, catastrophizing, kinesiophobia, poor coping strategies, poor self-efficacy, and pre-existing somatization [5-8]. Social factors include work absenteeism, isolation, legislation, compensation systems, and social and economic infrastructures $[5,9,10]$. 
There is a discrepancy between evidence-based guidelines for the management of low back pain and clinical practice $[3,11,12]$. Guidelines support multidisciplinary care for persistent low back pain including education, continuing with usual activities, exercise, manual therapy, and psychological treatments. This approach is more consistent with holistic care and the biopsychosocial model. However, care is often biomedical and fragmented with recommendations for rest and prescription medications [12]. It has been postulated that this translation gap facilitates the continued poor outcomes in low back pain management $[1,12]$.

Many different health care professions treat patients with low back pain, and students of these varied disciplines represent the future of pain management. Patients report that health care professionals have the strongest influence on their beliefs about LBP, thus provider beliefs dictate outcomes [13-15]. If students have adequate knowledge of psychological and social factors contributing to low back pain it is likely they will make more effective treatment recommendations that align with evidence-based guidelines. The purpose of this scoping review is to evaluate health science students' knowledge of psychosocial factors associated with low back pain.

\section{Methods}

Scoping review methodology as described by Arskey and O'Malley, and later revised by Levac then Tricco was utilized to collect and organize relevant information and then provide a comprehensive examination of the existing body of literature [16-18]. This is completed in 6 stages:

1. Identifying the research question

2. Identifying relevant studies

3. Study selection

4. Charting the data

5. Collating, summarizing, and reporting the results

6. Consulting with key stakeholders

We followed the recently standardized PRISMA-ScR extension by Tricco et al. (http://www.equator-network. org/reporting-guidelines/prisma-scr/) [18]. We deviated from the 6 steps proposed by Arksey and O'Malley because we have no key stakeholders to consult with. There is no mandatory scoping review registration of scoping review protocols.

Stage 1: identifying the research question

This review evaluated the question 'do health science students have knowledge of psychosocial factors associated with low back pain?'

Stage 2: identifying relevant studies

We searched the following electronic databases: PubMed, Google Scholar, EMBASE (Ovid), SINAHL, MEDLINE, Cochrane library, Index of Chiropractic Literature, and
PEDro from database inception to May 22, 2019. The 'related articles' features were utilized and references of all relevant papers were inspected. The search was completed using a combination of MeSH terms, keywords, and ChiroSH terms, which can be found in Appendix 1. Additionally, grey literature (e.g. conference proceedings) were searched using the same terms. Back pain belief and pain education were searched relative to the many health care disciplines and the associated student of those disciplines (physiotherapy, physical therapy, medicine, chiropractic, acupuncture, psychology, nursing, and social worker) that commonly treat low back pain.

Stage 3: study selection

All abstracts were screened independently by both authors (KL, PB). Publications identified as potential for inclusion were gathered in full-text and the same inclusion process was performed. Any disagreements on inclusion were resolved through discussion.

Inclusion criteria: participants were health science students of any discipline, and an assessment tool was utilized to measure their knowledge of psychosocial factors associated with low back pain.

Exclusion criteria: participants were not students (e.g. practitioners), no assessment tool was used to measure their knowledge of psychosocial factors associated with low back pain, or assessment of knowledge was not specific to low back pain.

Stage 4: charting the data

We classified the data based on author, year, study population, methodology, aims of the study, outcome measures, and results and conclusions. The research form was tested independently by the two authors to determine consistency, accuracy, and completeness of approach. There was no quality assessment, as there was much heterogeneity between publications and the goal was to assess the entirety of the literature on the topic.

Stage 5: collating, summarizing, and reporting the results

We analyzed the studies by determining how students were measured on their knowledge of psychosocial factors and where that measurement fell when compared to the minimum accepted score. From there we determined if students had adequate knowledge of psychosocial factors associated with low back pain.

Stage 6: considering our research question, we did not think it appropriate to consult with key stakeholders

\section{Results}

Fourteen studies were identified [19-32], published between 2004 and 2019. Students examined include: physical therapy (PT) alone $(n=4)$, PT compared with nursing $(n=1)$, PT compared with medical and nursing $(n=1)$, PT compared with occupational therapy (OT) and nursing $(n=1)$, PT compared with non-healthcare $(\mathrm{n}=1)$, medical alone $(n=3)$, medical compared to 
non-healthcare $(\mathrm{n}=1)$, osteopathy $(\mathrm{n}=1)$, and medical, chiropractic, OT, PT, and pharmacists were compared $(\mathrm{n}=1)$. In total, 4964 students were studied.

The main outcomes of each study are presented in Table 1. The following assessment tools were used: Healthcare Providers' Pain and Impairment Relationship Scale (HC-PAIRS) $(n=9)$; Back Pain Beliefs Questionnaire (BBQ) $(n=3)$; Questionnaire assessing likely practice behaviors $(n=1)$; 21-questions assess clinical judgement $(n=1)$; Interpersonal Reactivity Index (IRI): Empathy components $(n=1)$; Fear Avoidance Beliefs Questionnaire- Physical Activity component (FABQ-PA) $(n=1)$; an objective structured clinical examination (OSCE) $(n=1)$; Modified Back Pain Beliefs Questionnaire (MBBQ) $(n=1)$; Back Pain Attitudes Questionnaire (Back-PAQ) $(n=1)$; Pain Attitudes and Beliefs Scale (PABS) $(\mathrm{n}=1)$; and the Modified Photograph Series of Daily Activities (MPHODA) $(n=1)$.

In 9 studies students failed to demonstrate adequate knowledge of psychosocial factors associated with low back pain. With respect to the HC-PAIRS, students consistently scored higher than the recommended 38 , indicating more negative beliefs about disability and functional limitations due to low back pain [33]. The BBQ was used to compare disciplines and showed physical therapy consistently scored higher than medical, occupational therapy, pharmacy, and nursing students. Chiropractic students scored higher than occupational therapy, pharmacy, and nursing students in 1 study [24]. Higher scores indicate more positive beliefs about the future in patients with LBP [34]. The FABQ-PA and MPHODA were also used to compare disciplines. The former found that PT students have less fear-avoidant beliefs than medical and nursing students [26]. The latter demonstrated that PT students had significantly more positive beliefs where they considered activities of daily living to be less harmful for the low back than OT and nursing students [32]. The questionnaire to assess future practice behavior developed by Evans et al. (2005) was used to compare disciplines [35]. Chiropractic and physical therapy students were more likely to make 'guideline consistent' recommendations as compared to occupational therapy and pharmacy students. These recommendations correlated with HC-PAIRS and BBQ scores. Utilizing the Back-PAQ and HC-PAIRS, Hilbink determined that osteopathy students have less than optimal knowledge of psychosocial factors and beliefs about LBP that are not consistent with guidelines [30].

Chibnall et al. reported that students are more likely to recognize psychosocial factors at play when they have an ongoing relationship with the patient rather than a 1-time evaluation. [[25] In this study, students were seeing patients that were seeking disability. Students were either seeing the patients long-term (strong patient accountability), or 1-time (weak patient accountability). Additionally, the student was either the primary doctor being used to grant the patient disability (strong societal accountability) or they were the secondary doctor being seen (weak societal accountability). When patient and societal accountability were consistent (ie. both strong or both weak) students viewed psychosocial factors as playing a major role in the pain presentation. This was demonstrated using 4 clinical vignettes followed by the IRI-empathy components and the questionnaire with 21-items assessing clinical judgement [25].

Several studies demonstrated improvements in scores on various outcome measures as education advanced [20-23, 26, 30-32].

Several studies implemented educational modules ranging from $15-\mathrm{min}$ to 16 -h $[20,27,29]$. They all determined that knowledge of psychosocial factors and beliefs about LBP improve following the educational interventions. However, the HC-PAIRS scores were still sub-optimal in 1 study [20]. Weiner et al. utilized an OSCE and Abdel Shaheed et al. utilized the MBBQ to evaluate students pre- and post-educational intervention. Both demonstrated significant improvements. The former with a significant amount of students passing the LBP OSCE, and the latter with more students answering with positive beliefs and guideline-consistent answers on the MBBQ [27, 29].

\section{Discussion}

This scoping review highlights certain health science students' inadequate knowledge of psychosocial factors contributing to the development and persistence of low back pain regardless of discipline. Differences were seen between disciplines and nationalities. Students' knowledge of psychosocial factors seems to improve as their education advances, although still to a sub-optimal level in most. Dedicated pain education has potential to improve knowledge.

The leading cause of years lived with disability in both developed and undeveloped countries is low back pain, and $40 \%$ of adults report living with low back pain $[3,36]$. A 2006 review found that the total cost of low back pain exceeds $\$ 100$ billion yearly, and that two-thirds of these costs are due to lost wages and reduced productivity [37]. An impact of that magnitude necessitates better understanding of the multidimensional nature of low back pain to provide more precise and cost-effective care.

The biopsychosocial model describes the inseparable interaction between biological (somatic), psychological, and social contributors to a person's health [38, 39]. This is exemplified in low back pain as over $90 \%$ of diagnoses are non-specific, indicating a poor correlation between physical findings and pain [2]. Current guidelines for the management of non-specific low back pain support a biopsychosocial framework $[1,2,11]$. Our review demonstrates students' general lack of knowledge of psychosocial 


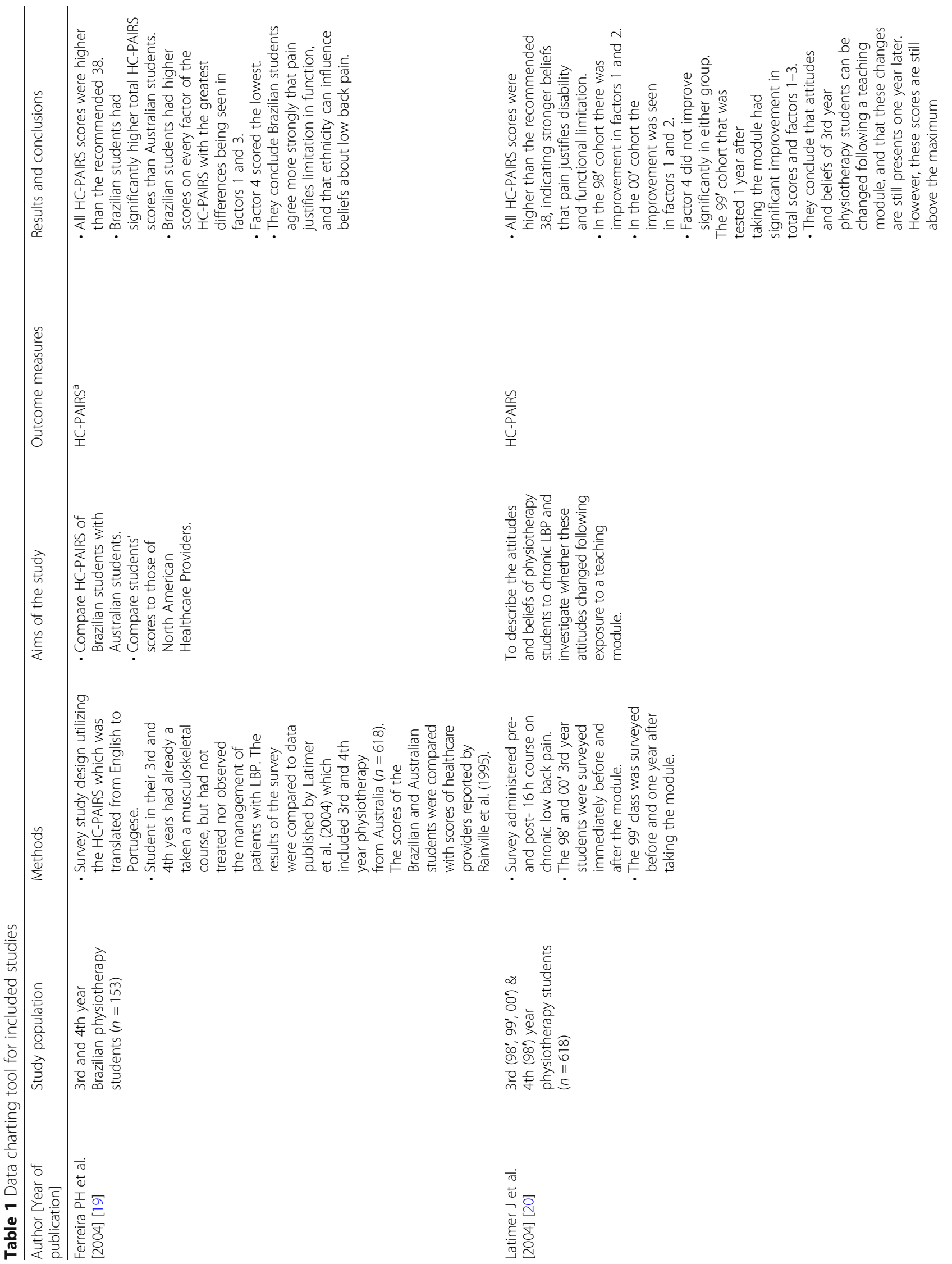




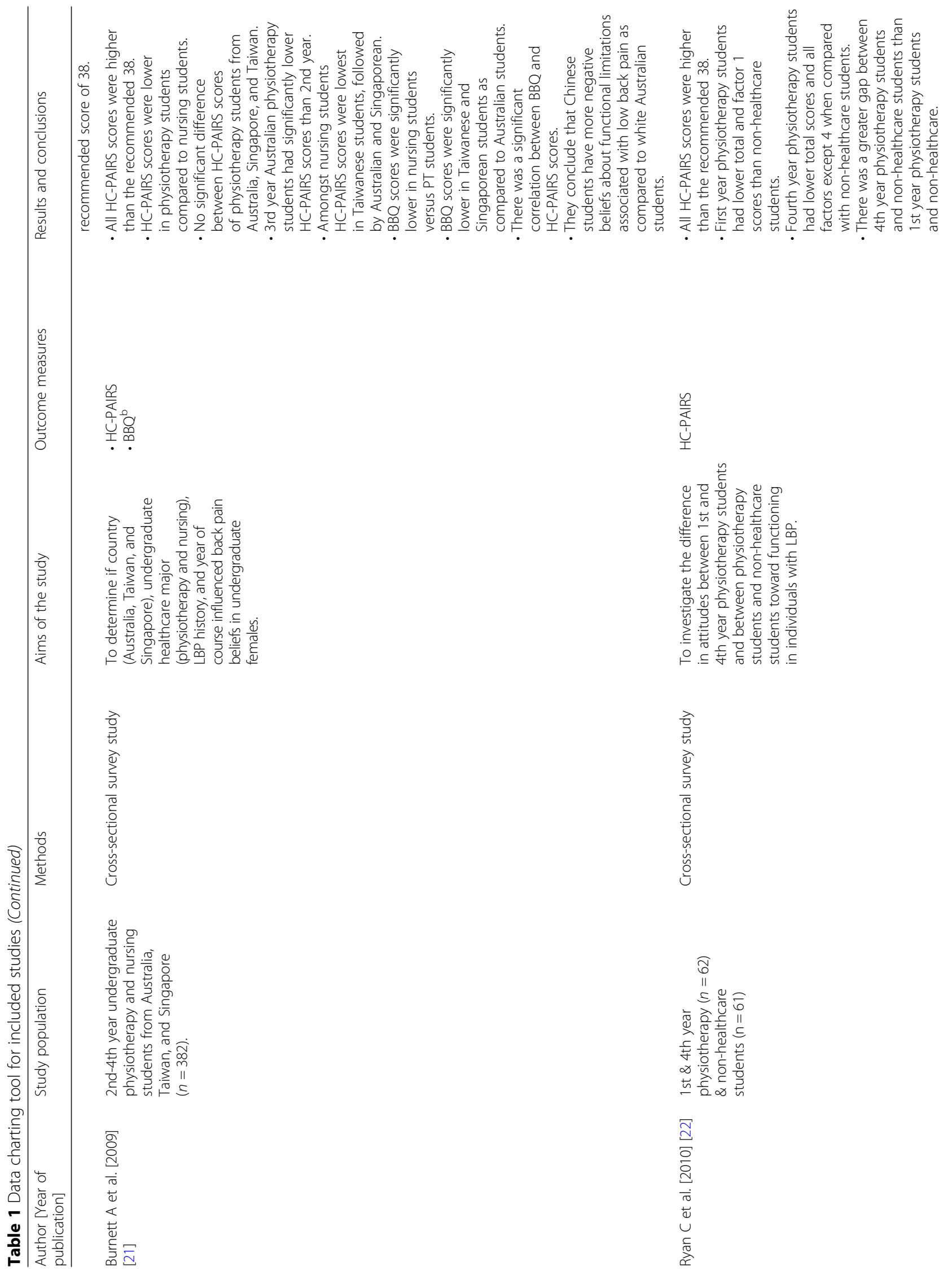




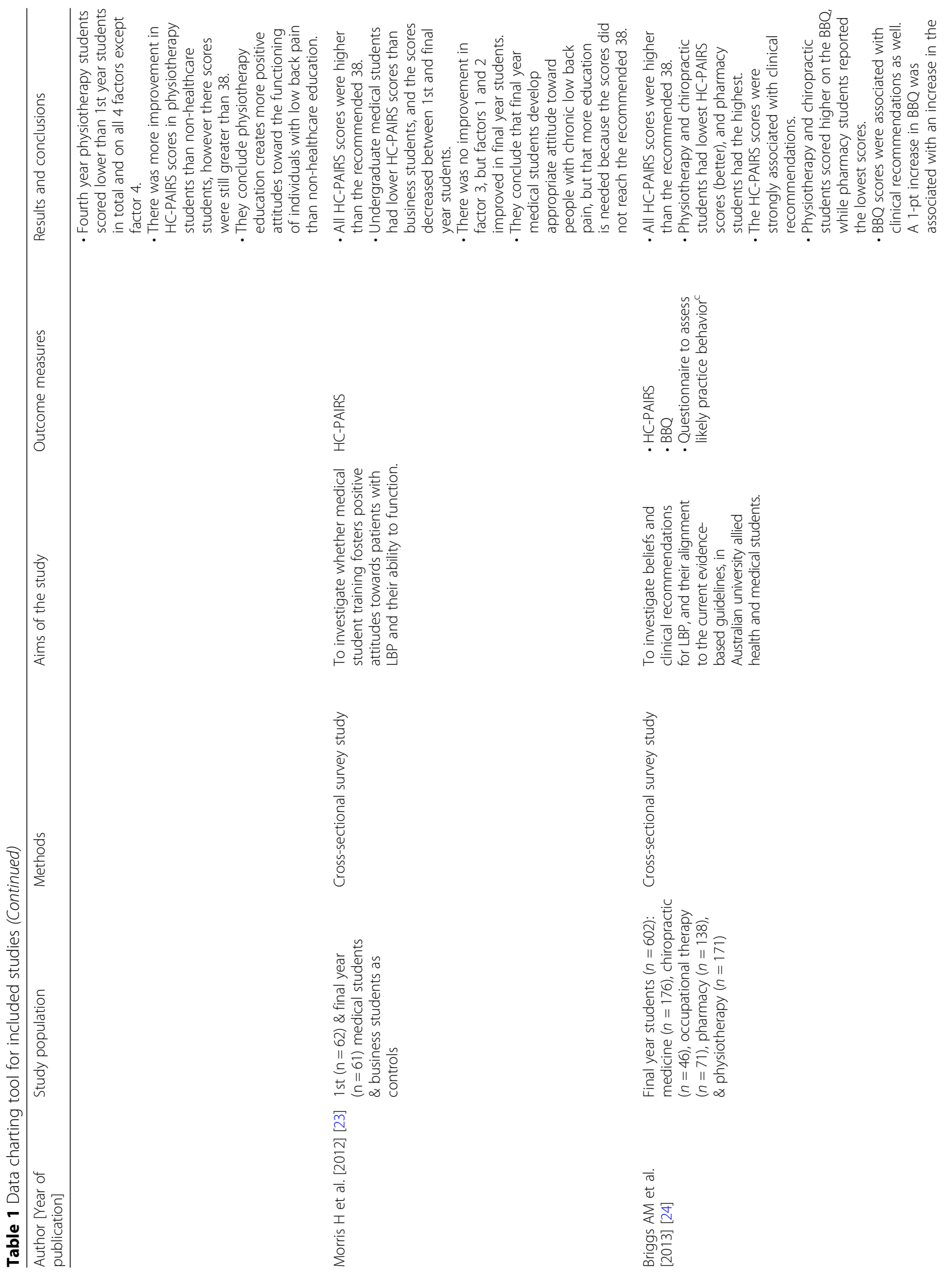




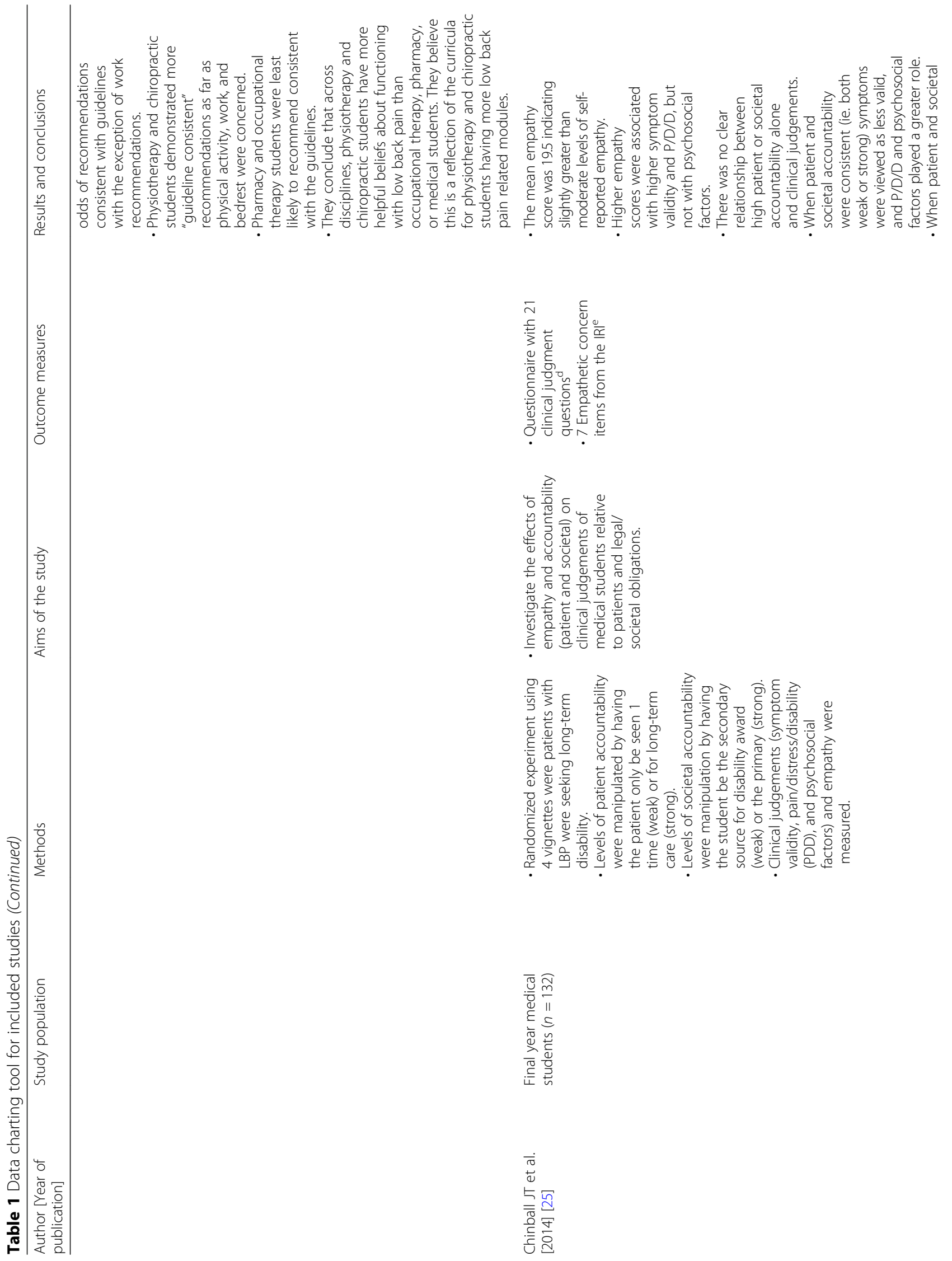




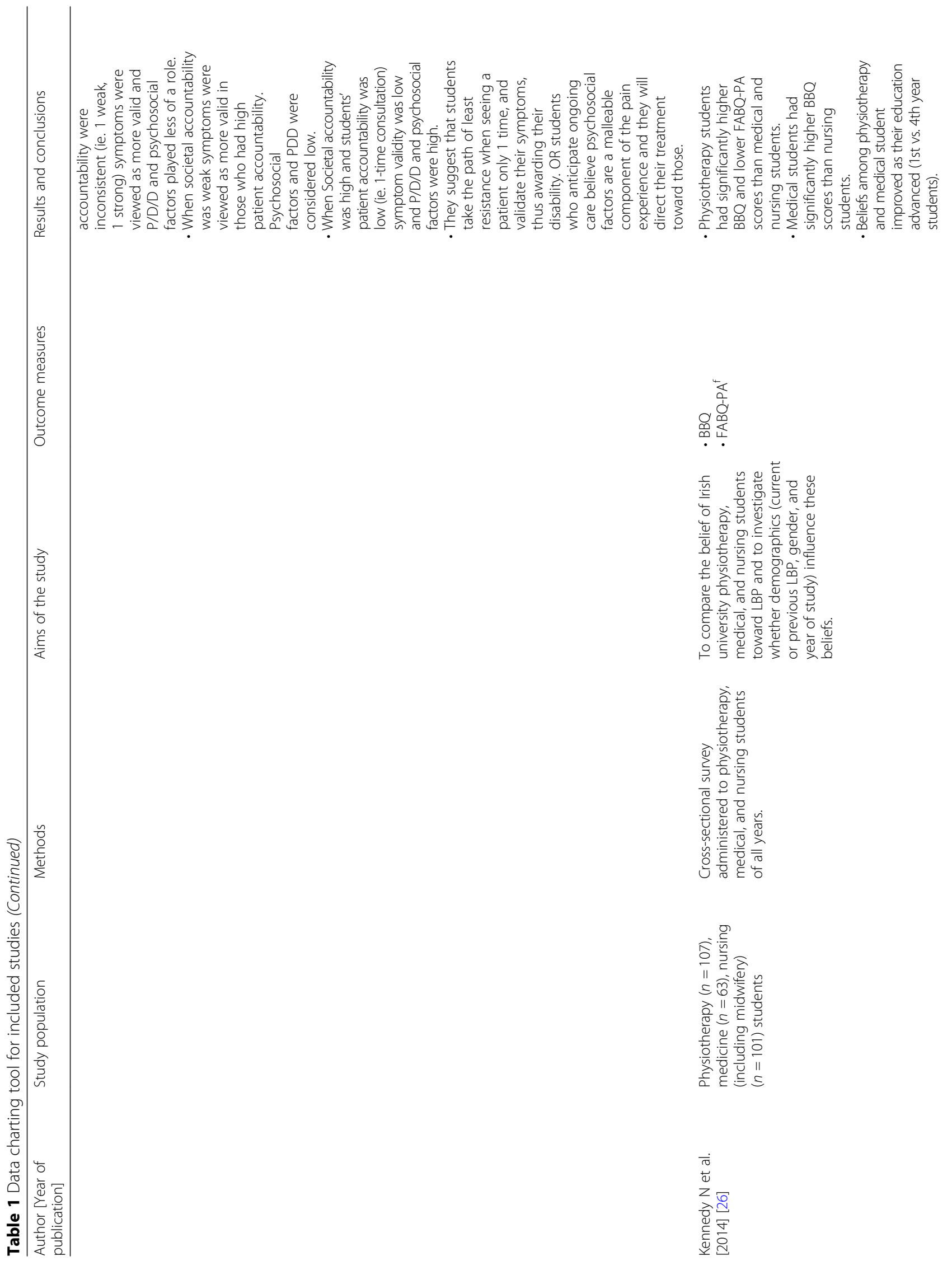




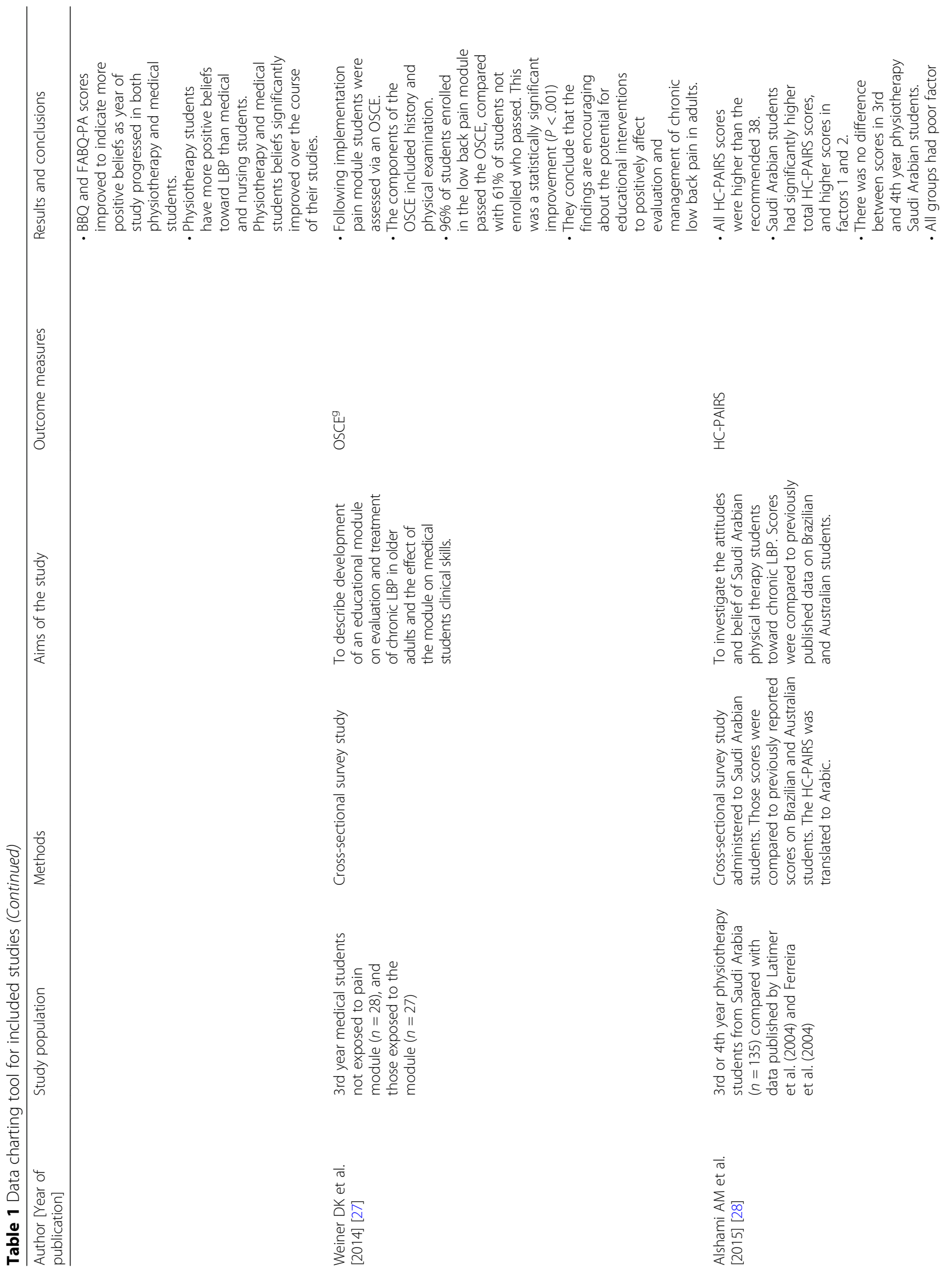




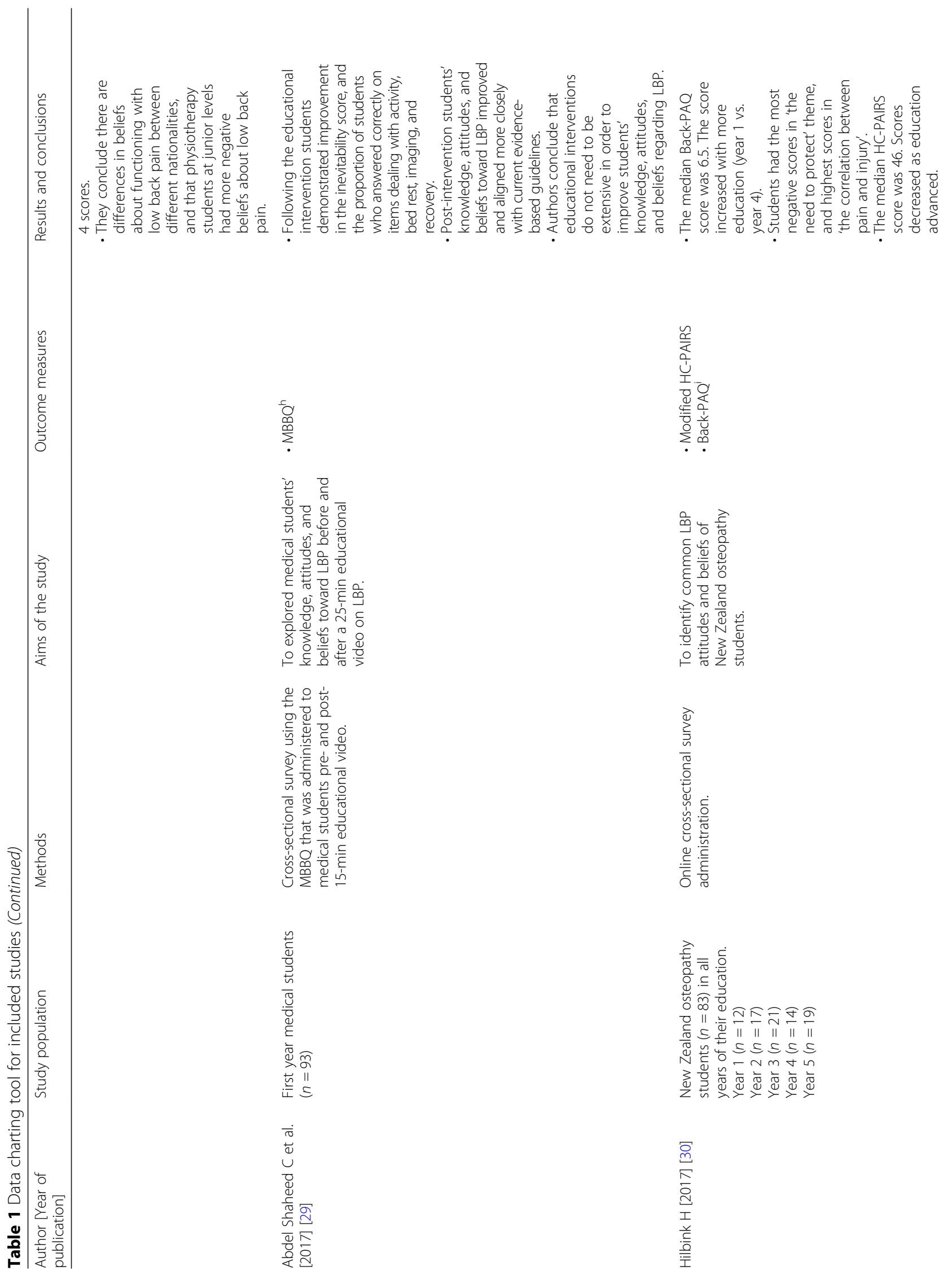




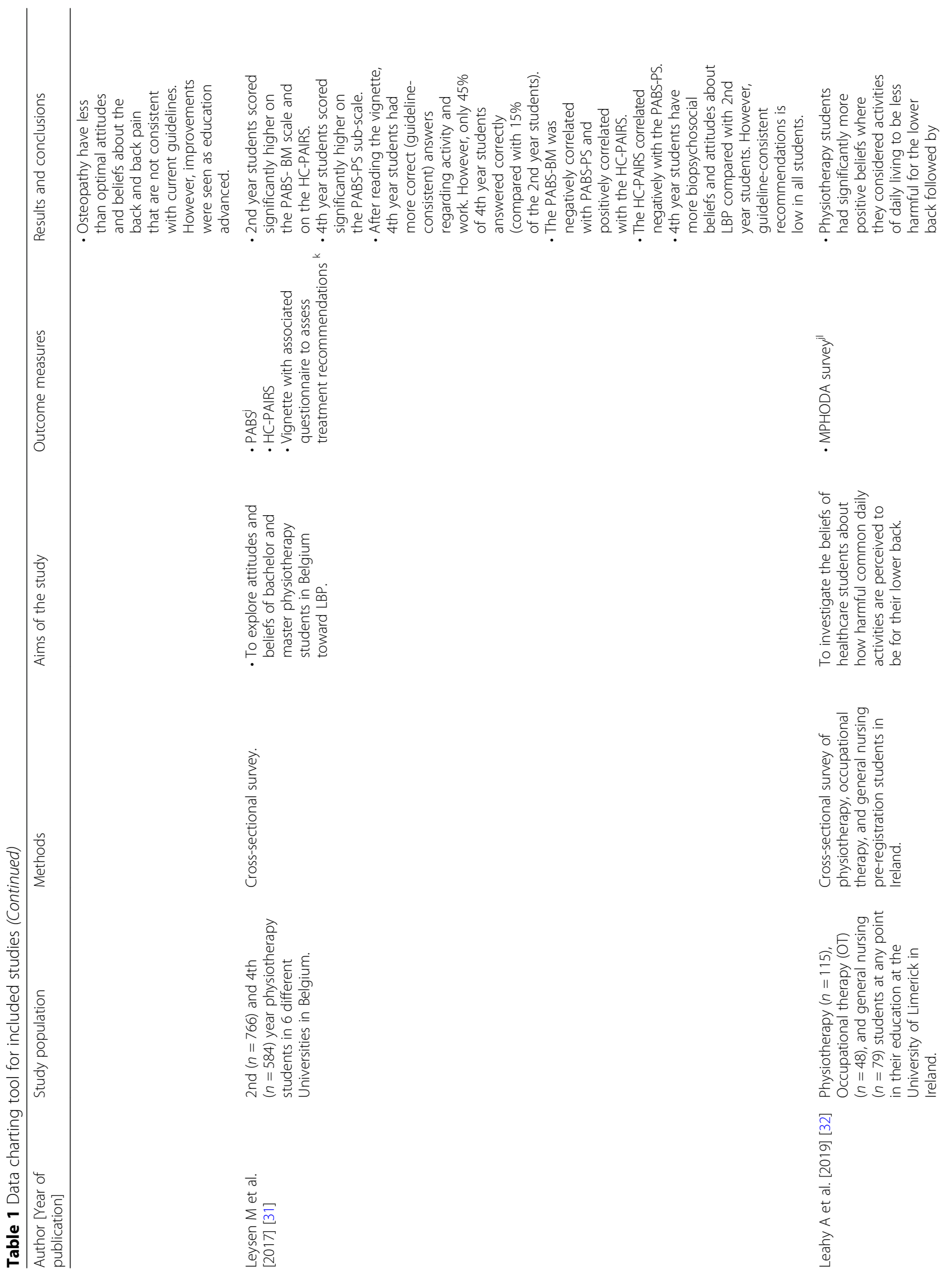




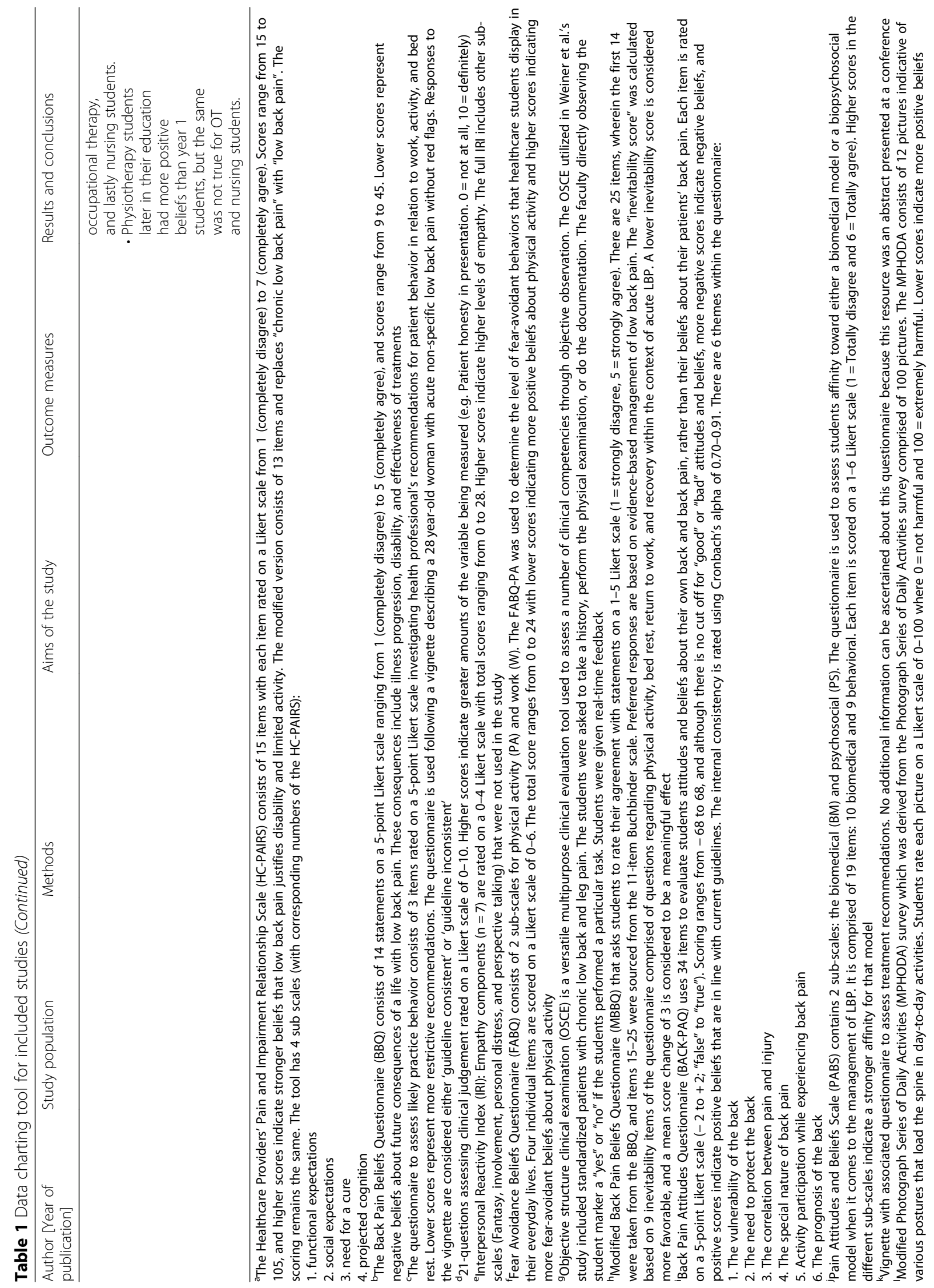


factors associated with low back pain. For low back pain treatment, there is a gap between evidence and practice, suggesting first-line treatments like promoting activity and function, including work participation are not being readily recommended [12]. For example, Rainville et al. found that the mean HC-PAIRS score of orthopedic surgeons and family physicians in the U.S. was 54 (i.e. higher than the recommended 38), and that this score was associated with inappropriate practice recommendations endorsing activity restrictions and rest [40]. Based on our results, more training is needed at the health science student level to improve their understanding of psychosocial factors associated with low back pain. Deliberate training on this topic may improve future practice recommendations.

In this review there was heterogeneity in evaluating students' knowledge. Several different measurement tools were utilized, none of which comprehensively measured the students' knowledge of psychological and social factors associated with low back pain. Several authors suggest removing factor 4 (projected cognition) from the HC-PAIRS after noting the poor correlation between factor 4 and the remaining factors, and thus questioning factor 4's psychometric value [19, 22, 24]. As for the $B B Q, F A B Q, M B B Q$, Back-PAQ, PABS, and MPHODA there are no set standard for the scoring system, but rather higher or lower scores indicating more negative or positive beliefs when compared across disciplines. A systematic review found that OSCEs are a valid way to test students, and they're advantageous for evaluating real-time clinical decision-making $[27,41]$.

Despite the lack of uniformity in assessing students, some conclusions can be made. Students from most health care disciplines lack satisfactory knowledge of psychosocial factors associated with low back pain. In a small sample, physical therapy and chiropractic students scored significantly better on the HC-PAIRS than occupational therapy, medical, and pharmacy students. Those same students were more likely to make 'guideline consistent' recommendations later in practice. Using the PABS-BM/PS, Leysen et al. discovered that 4th year PT students have more biopsychosocial beliefs than 2nd year, and that they're more likely to answer correctly with guideline-consistent responses. However, even in this study the correct responses were made by only $45 \%$ of 4 th year PT students. In general, physical therapy students demonstrate more positive beliefs about low back pain as compared to nursing, occupational therapy, and medical students. Differences in nationality were also associated with different HC-PAIRS scores. In general, Australian students had more positive beliefs, although still suboptimal, as compared to Brazilian, Singaporean, Taiwanese, and Saudi Arabian students. As students progress in their education they have improved HC-PAIRS, FABQ-PA, BackPAQ, and PABS scores, indicating health care education improves knowledge of psychosocial factors associated with low back pain. However, in the majority of the studies showing improvements the authors' conclude that students still need continuing education on guideline-consistent LBP care because the improvement seen was not significant. There was improvement following dedicated pain modules seen in Latimer et al., Weiner et al., and Abdel Shaheed et al. [20, $27,29]$ The first reported improved scores to still be suboptimal; the second indicated significant improvement in the number of students who passed the chronic low back pain OSCE; and the last reported improvements in knowledge, attitudes, and beliefs toward LBP and greater alignment with evidence-based guidelines. The OSCE included history and physical exam. There may be benefit of painspecific courses highlighting chronic pain and treatment which included addressing psychosocial factors. Future studies should determine the appropriate length and mode of teaching a pain course.

Interest in students understanding of the biopsychosocial model relating to pain has grown recently. A recent review of 20 studies evaluating students knowledge, skills, attitudes, or beliefs about pain across medicine, nursing, PT, and occupational therapy found that students lack these key components to adequately manage pain and many had negative attitudes and beliefs about pain [42].

Ultimately, care adhering to the biopsychosocial model should yield better outcomes [39]. Psychological interventions decrease disability and pain catastrophizing, and improve activity levels, pain control, and illness perceptions in patients with low back pain [43, 44]. A recent qualitative systematic review determining the effect of psychological interventions delivered by non-psychologists (e.g. physical and occupational therapists, and physicians) on low back pain and disability found significantly decreased low back pain and disability scores. However, when compared to guideline-informed usual care the psychological interventions were superior in only a few of the studies [45]. A study conducted at the Ford Motor plant discovered that through the use of mind-body practices (e.g. yoga and tai-chi) and acupuncture there was a $58 \%$ reduction in prescription medication for low back pain management [46]. Because this research is still in its infancy more work is needed to determine its true impact. However, psychosocial factors contribute to the development and persistence of low back pain, and targeted intervention may help relieve low back pain and suffering [5].

\section{Limitations}

Most students studied were physical therapy students. Because of this, the findings hold truer for this discipline as compared to disciplines that were not studied (e.g. clinical psychologists and surgical residents). This is an avenue for future research to evaluate all health science students' knowledge of psychosocial factors associated with low back pain. 


\section{Conclusions}

Students across many healthcare disciplines do not have adequate knowledge of psychosocial factors associated with low back pain. Therefore, it is likely that suboptimal low back pain care will persist. Future research should determine the most effective way to implement pain courses in the curricula of health science students and evaluate the outcomes of these pain courses as they relate to improvement in student understanding and ultimately outcomes in low back pain care.

\section{Appendix}

\section{Electronic database search strategy}

1. Psychosocial AND back AND students

2. Psychosocial AND back AND education

3. Attitudes and beliefs AND education

4. Back AND healthcare student belief

5. Back pain belief AND

1. Physiotherapy

2. Physiotherapy student

3. Physical therapy

4. Physical therapy student

5. Medical doctor

6. Medical student

7. Chiropractor

8. Chiropractic student

9. Acupuncture

10. Psychologist

11. Psychology student

12. Pain psychologist

13. Pain psychology student

14. Nursing

15. Nursing student

16. Social working

6. Student beliefs about back pain

7. Back pain attitude AND student

8. Pain education AND

1. Physiotherapy student

2. Physical therapy student

3. Medical student

4. Chiropractic student

5. Psychology student

6. Nursing student

7. Social worker

9. Back pain education AND

1. Student

2. Physiotherapy student

3. Physical therapy student

4. Medical student

5. Chiropractic student

6. Psychology student

7. Nursing student

8. Social worker

\section{Abbreviations}

Back-PAQ: Back Pain Attitudes Questionnaire; BBQ: Back pain beliefs questionnaire; FABQ: Fear Avoidance Beliefs Questionnaire; FABQ-PA: Fear Avoidance Beliefs Questionnaire- Physical activity; HC-PAIRS: Health care providers' pain and impairment relationship scale; IRI: Interpersonal Reactivity Index; MBBQ: Modified Back Pain Beliefs Questionnaire; MPHODA: Modified Photograph Series of Daily Activities; OSCE: Objective structured clinical examination; OT: Occupational therapy; PABS: Pain Attitudes and Beliefs Scale; PT: Physical therapy

\section{Acknowledgements}

Norman W. Kettner, DC for providing edits to the final manuscript. Clinton Daniels, DC for providing direction regarding scoping review methodology.

\section{Authors' contributions}

$\mathrm{KLL}$ and PBJ performed the literature search, analyzed results, drafted, revised, and approved the final manuscript.

\section{Funding}

Not applicable.

\section{Availability of data and materials}

Data sharing is not applicable to this article as no datasets were generated or analyzed during the current study.

Ethics approval and consent to participate

Not applicable.

Consent for publication

Not applicable.

\section{Competing interests}

The authors declare they have no competing interests.

Received: 22 December 2018 Accepted: 1 October 2019

Received:

\section{References}

1. Hartvigsen J, Hancock MJ, Kongsted A, Louw Q, Ferreira ML, Genevay S, et al. What low back pain is and why we need to pay attention. Lancet. 2018;391(10137):2356-67.

2. Maher C, Underwood M, Buchbinder R. Non-specific low back pain. Lancet. 2017;389:736-848.

3. Hoy D, March L, Brooks P, Blyth F, Woolf A, Bain C, et al. The global burden of low back pain: estimates from the global burden of Disease 2010 study. Ann Rheum Dis. 2014;73(6):968-74.

4. Disease GBD, Injury I, Prevalence C. Global, regional, and national incidence, prevalence, and years lived with disability for 310 diseases and injuries, 1990-2015: a systematic analysis for the global burden of Disease study 2015. Lancet. 2016;388(10053):1545-602.

5. Pincus T, Kent P, Bronfort G, Loisel P, Pransky G, Hartvigsen J. Twenty-five years with the biopsychosocial model of low back pain-is it time to celebrate? A report from the twelfth international forum for primary care research on low back pain. Spine. 2013;38(24):2118-23.

6. Arnold LM, Hudson Jl, Keck PE, Auchenbach MB, Javaras KN, Hess EV. Comorbidity of fibromyalgia and psychiatric disorders. J Clin Psychiatry 2006;67(8):1219-1225. PubMed PMID: 16965199.

7. Generaal E, Vogelzangs N, Penninx BW, Dekker J. Insomnia, sleep duration, depressive symptoms, and the onset of chronic multisite musculoskeletal pain. Sleep 2017 1;40(1). PubMed PMID: 28364456.

8. Leung L. Pain catastrophizing: an updated review. Indian J Psychol Med 2012;34(3):204-217. PubMed PMID: 23441031. Pubmed Central PMCID: 3573569

9. Eisenberger NI. The pain of social disconnection: examining the shared neural underpinnings of physical and social pain. Nat Rev Neurosci. 2012; 13(6):421-34.

10. Sturgeon JA, Dixon EA, Darnall BD, Mackey SC. Contributions of physical function and satisfaction with social roles to emotional distress in chronic pain: a collaborative health outcomes information registry (CHOIR) study. Pain. 2015;156(12):2627-33. 
11. Buchbinder R, van Tulder M, Oberg B, Costa LM, Woolf A, Schoene M, et al. Low back pain: a call for action. Lancet. 2018;391(10137):2384-8.

12. Foster NE, Anema JR, Cherkin D, Chou R, Cohen SP, Gross DP, et al. Prevention and treatment of low back pain: evidence, challenges, and promising directions. Lancet. 2018;391(10137):2368-83.

13. Darlow B, Dowell A, Baxter GD, et al. The enduring impact of what clinicians say to people with low back pain. Ann Fam Med. 2013;11:527-34.

14. Coudeyre E, Rannou F, Tubach F, et al. General practitioners' fear avoidance beliefs influence their management of patients with low back pain. Pain. 2006;124:330-7.

15. Gardner T, Refshauge K, Smith L, et al. Physiotherapists' beliefs and attitudes influence clinical practice in chronic low back pain: a systematic review of quantitative and qualitative studies. J Physiother. 2017;63:132-43.

16. Arksey H, O'Malley L. Scoping studies: towards a methodological framework. Int J Soc Res Methodol. 2005;8(1):19-32.

17. Levac D, Colquhoun H, O'Brien KK. Scoping studies: advancing the methodology. Implement Sci. 2010;5:69.

18. Tricco AC, Lillie E, Zarin W, O'Brien KK, Colquhoun H, Levac D, et al. PRISMA extension for scoping reviews (PRISMA-SCR): checklist and explanation. Ann Intern Med. 2018;169(7):467-73.

19. Ferreira PH, Ferreira ML, Latimer J, Maher CG, Refshauge K, Sakamoto A et al. Attitudes and beliefs of Brazilian and Australian physiotherapy students towards chronic back pain: a cross-cultural comparison. Physiother Res Int. 2004;9(1):13-23.

20. Latimer J, Maher C, Refshauge K. The attitudes and beliefs of physiotherapy students to chronic back pain. Clin J Pain. 2004;20(1):45-50.

21. Burnett E. Perceptions, attitudes, and behavior towards patient hand hygiene. Am J Infect Control. 2009;37(8):638-42.

22. Ryan C, Murphy D, Clark M, Lee A. The effect of a physiotherapy education compared with a non-healthcare education on the attitudes and beliefs of students towards functioning in individuals with back pain: an observational, cross-sectional study. Physiotherapy. 2010;96(2):144-50.

23. Morris H, Ryan C, Lauchlan D, Field M. Do medical student attitudes towards patients with chronic low back pain improve during training? A cross-sectional study. BMC Med Educ. 2012;12:10

24. Briggs AM, Slater H, Smith AJ, Parkin-Smith GF, Watkins $K$, Chua J. Low back pain-related beliefs and likely practice behaviours among final-year crossdiscipline health students. Eur J Pain. 2013;17(5):766-75.

25. Chibnall JT, Tait RC, Jovel A. Accountability and empathy effects on medical students' clinical judgments in a disability determination context for low Back pain. J Pain. 2014;15(9):915-24.

26. Kennedy N, Healy J, O'Sullivan K. The Beliefs of Third-Level Healthcare Students towards Low-Back Pain. Pain research and treatment. 2014;doi: https://doi.org/10.1155/2014/675915

27. Weiner DK, Morone NE, Spallek H, Karp JF, Schneider M, Washburn C, et al. E-learning module on chronic low back pain in older adults: evidence of effect on medical student objective structured clinical examination performance. J Am Geriatr Soc. 2014;62(6):1161-7.

28. Alshami AM, Albrahani YA. A comparison of the attitudes toward chronic low back pain in Saudi, Australian and Brazilian physical therapy students. J Taibah Univ Med Sci. 2015:10(2):181-7.

29. Abdel Shaheed C, Graves J, Maher C. The effects of a brief educational intervention on medical students' knowledge, attitudes and beliefs towards low back pain. Scand J Pain. 2017;16:101-4.

30. Hilbink $\mathrm{H}$. An investigation of attitudes and underlying beliefs toward low Back pain among osteopathy students using the Back pain attitudes questionnaire (Back-PAQ). A thesis submitted in partial fulfilment of the requirements for the degree of Master of Osteopathy, Unitec Institute of Technology, 2017.

31. Leysen M, Nijs J, Van Wilgen P, Demoulin C, Danneels L, Voogt L, Dankaerts W, Pitance $L$, Roussel NA. Attitudes and beliefs concerning low back pain among physiotherapy students in Belgium: a cross-sectional study. Musculoskeletal Sci Pract. 2017;28:e3-e27.

32. Leahy A, O'Keeffe M, Robinson K, O'Sullivan $K$. The beliefs of healthcare students about the harmfulness of daily activities for their back: a crosssectional study. European journal of physiology. 2019;doi: https://doi.org/10. 1080/21679169.2019.1630854

33. Rainville J, Bagnall D, Phalen L. Health care providers' attitudes and beliefs about functional impairments and chronic back pain. Clin J Pain 1995 Dec 11(4):287-295. PubMed PMID: 8788576.
34. Symonds TL, Burton AK, Tillotson KM, Main CJ. Do attitudes and beliefs influence work loss due to low back trouble? Occup Med 1996:46(1):25-32. PubMed PMID: 8672790.

35. Evans DW, Foster NE, Underwood M, Vogel S, Breen AC, Pincus T. Testing the effectiveness of an innovative information package on practitioner reported behaviour and beliefs: the UK chiropractors, osteopaths and musculoskeletal physiotherapists low back pain ManagemENT (COMPLeMENT) trial [ISRCTN77245761]. BMC Musculoskelet Disord. 2005;6:41.

36. Hoy D, Bain C, Williams G, March L, Brooks P, Blyth F, et al. A systematic review of the global prevalence of low back pain. Arthritis Rheum. 2012; 64(6):2028-37.

37. Katz JN. Lumbar disc disorders and low-back pain: socioeconomic factors and consequences. J Bone Joint Surg Am. 2006;88(Suppl 2):21-4.

38. Engel GL. The biopsychosocial model and the education of health professionals. Ann N Y Acad Sci. 1978;310:169-87.

39. Engel GL. The clinical application of the biopsychosocial model. Am J Psychiatry. 1980;137(5):535-44.

40. Rainville J, Carlson N, Polatin P, Gatchel RJ, Indahl A. Exploration of physicians' recommendations for activities in chronic low back pain. Spine. 2000;25(17):2210-20.

41. Patricio MF, Juliao M, Fareleira F, Carneiro AV. Is the OSCE a feasible tool to assess competencies in undergraduate medical education? Med Teach. 2013;35(6):503-14

42. Thompson K, Johnson Ml, Milligan J. Twenty-five years of pain education research - what have we learned? Findings from a comprehensive scoping review of research into pre-registration pain education for health professionals. Pain. 2018;159:2146-58.

43. Mansell G, Storheim K, Lochting I, Werner EL, Grotle M. Identification of indirect effects in a cognitive patient education (COPE) intervention for low Back pain. Physical therapy. 2017;97(12):1138-46. PubMed PMID: 29186635. Pubmed Central.

44. Spinhoven P, Ter Kuile M, Kole-Snijders AM, Hutten Mansfeld M, Den Ouden DJ, Vlaeyen JW. Catastrophizing and internal pain control as mediators of outcome in the multidisciplinary treatment of chronic low back pain. Eur J Pain. 2004:8(3):211-9.

45. Bostick GP. Effectiveness of psychological interventions delivered by nonpsychologists on low back pain and disability: a qualitative systematic review. Spine J. 2017;17(11):1722-8.

46. Kimbrough E, Lao L, Berman B, Pelletier KR, Talamonti WJ. An integrative medicine intervention in a Ford Motor Company assembly plant. J Occup Environ Med. 2010;52(3):256-7.

\section{Publisher's Note}

Springer Nature remains neutral with regard to jurisdictional claims in published maps and institutional affiliations.

Ready to submit your research? Choose BMC and benefit from:

- fast, convenient online submission

- thorough peer review by experienced researchers in your field

- rapid publication on acceptance

- support for research data, including large and complex data types

- gold Open Access which fosters wider collaboration and increased citations

- maximum visibility for your research: over $100 \mathrm{M}$ website views per year

At $\mathrm{BMC}$, research is always in progress.

Learn more biomedcentral.com/submissions 